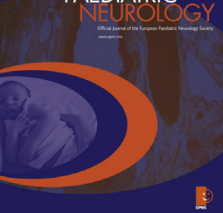

Original article

\title{
Age-related prevalence and features of migraine headache in Hungarian schoolchildren and adolescents
}

\author{
Jenố Kóbor ${ }^{a, *}$, Tibor Nyári ${ }^{b}$, György Benedek ${ }^{c}$, Sándor Túri ${ }^{a}$ \\ a Department of Paediatrics, Faculty of Medicine, University of Szeged, Szeged, Hungary \\ ${ }^{\mathrm{b}}$ Department of Medical Physics and Informatics, Faculty of Medicine, University of Szeged, Szeged, Hungary \\ ${ }^{\mathrm{c}}$ Department of Physiology, Faculty of Medicine, University of Szeged, Szeged, Hungary
}

\section{A R T I C L E I N F O}

\section{Article history:}

Received 13 October 2012

Received in revised form

5 May 2013

Accepted 9 May 2013

\section{Keywords:}

Migraine

Schoolchildren

Prevalence

Symptoms

Brain maturation

\begin{abstract}
A B S T R A C T
Background: Differences occur in certain features of childhood and adult migraine, such as the duration and location. However, few studies have been reported of the changes in other symptoms during childhood.

Aims: The aims of this study were to establish the prevalence of migraine headache in children in Hungary, and to investigate the changes in prevalence of migraine and migraine symptoms in a wide paediatric age range.

Methods: We conducted a school-based study with the use of a questionnaire.

Results: 7361 7-18-year-old students participated. The 1-year prevalence of migraine was $12.5 \%$ (9.2\% in boys and $15.4 \%$ in girls). With the criterion of a headache duration of $4 \mathrm{~h}$ for 15-18-year-olds and of $1 \mathrm{~h}$ below the age of 15, the overall prevalence decreased to $9.1 \%$. The prevalence of migraine increased steadily from young childhood to late adolescence in both boys and girls. The frequency and duration of headache increased, whereas vomiting and nausea became less prevalent with advancing age in both genders. The prevalence of uni/bilaterality, photophobia and phonophobia increased only in girls, while that of a pulsating character did so only in boys.

Conclusions: The migraine characteristics displayed by the studied population proved similar to those experienced in other countries. The duration of headache applied in the diagnosis of migraine exerts a great impact on the prevalence data. The features of migraine change with advancing age, a situation demanding consideration in studies on migraine in children of different ages.
\end{abstract}

(c) 2013 European Paediatric Neurology Society. Published by Elsevier Ltd. All rights

reserved.

\section{Introduction}

The prevalence of migraine has been amply investigated in adulthood, but fewer data have been published in childhood.
After 1988, the case definition in most epidemiological studies was based on the strict or modified criteria set by the International Headache Society ${ }^{1}$ (IHS-1), but following the modifications in 2004 (International Classification of

\footnotetext{
* Corresponding author. Department of Paediatrics, Szeged, Korányi fasor 14, H-6725, Hungary. Tel.: +36 62545334 ; fax: +36 62545329 .

E-mail address: kobor.jeno@med.u-szeged.hu (J. Kóbor).

1090-3798/\$ - see front matter @ 2013 European Paediatric Neurology Society. Published by Elsevier Ltd. All rights reserved. http://dx.doi.org/10.1016/j.ejpn.2013.05.006
} 
Headache Disorders 2nd edition ${ }^{2}$ - ICHD-II), a headache duration as short as $1 \mathrm{~h}$ and a bilateral location have been accepted in children. These changes were expected to render a higher sensitivity for this diagnostic system. However, only a few data have been published subsequently.

As the duration and location of migraine headache may differ in children and adults, the question arises of whether other characteristics also change during childhood. We set out to establish the prevalence and features of headache through the use of ICHD-II in a large sample of schoolchildren and adolescents in Hungary. We additionally analysed the prevalence of headache and the frequency of the major symptoms in various age groups among these children, in order to identify any changes that occur with advancing age.

\section{Patients and methods}

\subsection{Study population}

This cross-sectional school-based study was performed in the city of Szeged, the regional centre of South-Eastern Hungary, with 170,285 inhabitants. Of the total of 12,094 primary school pupils, all 9234 attending one of the 21 municipalitymaintained schools were invited to participate. High schools were selected by a two-stage stratified cluster sampling method, which resulted in a total of 6178 pupils being invited to participate, i.e. $52 \%$ of the total.

\subsection{Questionnaire}

A questionnaire consisting of 37 questions was compiled. After taking birth date and gender, the children were asked if they had ever had headaches more than one time, not connected with febrile illness or head injury. Further questions concerning headache during the preceding 12 months involved the pain characteristics. The children took the questionnaires home to complete them together with their parents.

After approval had been granted by the city authorities, the school directors and the Ethical Committee of Szeged University, the study was performed in April and May, 2011.

\subsection{Validation of the questionnaire data}

328 randomly selected parents and students were contacted via telephone, and the headache-related questions were asked again. This revealed $83.2 \%$ sensitivity, $92.6 \%$ specificity, and $85.5 \%$ positive and $91.3 \%$ negative predictive values of the questionnaire responses.

\subsection{Data analysis}

For the diagnosis of migraine the ICHD-II criteria were applied. A time limit of a minimum headache duration of $1 \mathrm{~h}$ was set for the 7-14-year-olds. For the 15-18-year age groups, the prevalence was calculated with a minimum duration of both $1 \mathrm{~h}$ and $4 \mathrm{~h}$. No distinction was made between migraine with or without aura. In the calculations on the headache features, a diagnosis of migraine was accepted with a minimum headache duration of $1 \mathrm{~h}$ in all age groups.

For statistical analyses, SSPS for Windows (version 17.0) was used. The trends of the changes in the migraine prevalence data were assessed by Poisson regression (incidence rate ratio (IRR) and 95\% confidence interval (95\% CI)). For comparison with the results of other authors' we performed the same calculation when sufficient data were available. The trends of the changes in frequency of various migraine features were estimated by using logistic regression (odds ratio (OR) and 95\% $\mathrm{CI})$, and those with significant changes were further evaluated by multiple regression analysis. For the evaluation of changes in headache frequency and duration, Pearson's chi-square test was used.

\section{Results}

A total of 15,412 questionnaires were distributed, and 7361 that were appropriate for evaluation were returned. The overall response rate was $48 \%, 56.3 \%$ from primary school pupils, most of them under 15, and 34.6\% from high school pupils. 3465 $(47.1 \%)$ of the respondents were boys and 3896 (52.9\%) were girls (Table 1). As the overall response rate was relatively low, we compared the prevalence of migraine in the 8 primary schools with the highest response rate $(70 \%)$ with that for all of the pupils of the same age: $9.3 \%$ and $9.2 \%$, respectively.

\subsection{Prevalence of migraine headache}

With a minimum headache duration of $1 \mathrm{~h}$, we found 917 migrainous pupils in the overall population, 318 boys and 599 girls. The overall 12-month prevalence was $12.5 \%$ : $9.2 \%$ among boys and $15.4 \%$ among girls. Migraine was more common in the high-school pupils (20.5\%) than in the 7-14-year age group (9.2\%).

In contrast with ICHD-II, where no age limit but 'childhood' was applied for a headache duration of $1 \mathrm{~h}$, the IHS-1 classification accepted a duration of $2 \mathrm{~h}$ for migraine diagnosis only 'under the age of 15'. Calculation with this second approach, i.e. applying a $4-\mathrm{h}$ limit over the age of 15 , but accepting a duration of only $1 \mathrm{~h}$ under that age resulted in a significant decrease in the number of migraineurs to 668 , yielding an overall prevalence of $9.1 \%$ (7.3\% in boys and $10.6 \%$ in girls).

\subsection{Age and gender-related prevalence}

A steady increase in prevalence was found from 7 up to 18 years, both overall (IRR: 1.15, 95\% CI: $1.13-1.18, p<0.001$ ), and in each gender, at a higher rate in girls (IRR: 1.20, 95\% CI: $1.17-1.23, p<0.001$ ) than in boys (IRR: $1.07,95 \%$ CI: 1.04-1.11, $p<0.001$ ) (Table 1).

With the use of a minimum headache duration of $4 \mathrm{~h}$ for the diagnosis of migraine over the age of 14 , the continuous rise in the yearly prevalence dropped abruptly at the age of 15 years, and then resumed at the previous rate (IRR: 1.16, 95\% CI: 1.03-1.21, $p=0.007)$.

Most of the published studies that used the IHS-1 or ICHDII criteria revealed a steady increase in the age-specific prevalence data (Fig. 1). ${ }^{3-15}$ Poisson regression analysis of data 
Table 1 - Prevalence of migraine overall and in the individual age and gender groups.

\begin{tabular}{|c|c|c|c|c|c|c|c|c|c|c|c|}
\hline \multirow[t]{2}{*}{$\begin{array}{l}\text { Age } \\
\text { (years) }\end{array}$} & \multicolumn{3}{|c|}{ All respondents } & \multicolumn{4}{|c|}{$\begin{array}{c}\text { Migraine pupils } \\
\text { (duration }>1 \mathrm{~h} \text { in all age groups) }\end{array}$} & \multicolumn{4}{|c|}{$\begin{array}{c}\text { Migraine pupils } \\
\text { (duration }>4 \mathrm{~h} \text { in those over } 15 \text { years) }\end{array}$} \\
\hline & $\begin{array}{c}\text { Boys }+ \text { girls } \\
n\end{array}$ & $\begin{array}{c}\text { Boys } \\
n\end{array}$ & $\begin{array}{c}\text { Girls } \\
n\end{array}$ & $\begin{array}{c}\text { Boys }+ \text { girls } \\
n(\%)\end{array}$ & $\begin{array}{l}\text { Boys } \\
n(\%)\end{array}$ & $\begin{array}{l}\text { Girls } \\
n(\%)\end{array}$ & $p$ value & $\begin{array}{c}\text { Boys }+ \text { girls } \\
n(\%)\end{array}$ & $\begin{array}{l}\text { Boys } \\
n(\%)\end{array}$ & $\begin{array}{l}\text { Girls } \\
n(\%)\end{array}$ & $p$ value \\
\hline 7 & 557 & 249 & 308 & $20(3.6)$ & $8(3.2)$ & $12(3.9)$ & 0.27 & $20(3.6)$ & $8(3.2)$ & $12(3.9)$ & 0.27 \\
\hline 8 & 657 & 333 & 324 & $34(5.2)$ & $11(3.3)$ & $23(7.1)$ & $<0.001^{\mathrm{a}}$ & $34(5.2)$ & $11(3.3)$ & $23(7.1)$ & $<0.001^{a}$ \\
\hline 9 & 701 & 348 & 353 & $46(6.6)$ & $26(7.5)$ & $20(5.7)$ & 0.20 & $46(6.6)$ & $26(7.5)$ & $20(5.7)$ & 0.20 \\
\hline 10 & 728 & 391 & 337 & 75 (10.3) & $35(9.0)$ & 40 (11.9) & $0.022^{\mathrm{a}}$ & $75(10.3)$ & $35(9.0)$ & 40 (11.9) & $0.022^{a}$ \\
\hline 11 & 663 & 328 & 335 & 66 (10.0) & $31(9.5)$ & $35(10.4)$ & 0.27 & 66 (10.0) & $31(9.5)$ & 35 (10.4) & 0.27 \\
\hline 12 & 656 & 332 & 324 & 78 (11.9) & 37 (11.1) & 41 (12.7) & 0.19 & 78 (11.9) & 37 (11.1) & 41 (12.7) & 0.19 \\
\hline 13 & 698 & 334 & 364 & 89 (12.8) & $30(9.0)$ & $59(16.2)$ & $<0.001^{\mathrm{a}}$ & 89 (12.8) & $30(9.0)$ & $59(16.2)$ & $<0.001^{a}$ \\
\hline 14 & 565 & 273 & 292 & 71 (12.6) & 32 (11.7) & 39 (13.4) & 0.20 & 71 (12.6) & 32 (11.7) & 39 (13.4) & 0.20 \\
\hline $7-14$ & 5225 & 2588 & 2637 & 479 (9.2) & $210(8.1)$ & $269(10.2)$ & $<0.001^{\mathrm{a}}$ & $479(9.2)$ & $210(8.1)$ & $269(10.2)$ & $<0.001^{\mathrm{a}}$ \\
\hline 15 & 607 & 249 & 358 & $112(18.5)$ & $33(13.3)$ & 79 (22.1) & $<0.001^{\mathrm{a}}$ & $40(6.6)$ & $13(5.2)$ & $27(7.5)$ & $<0.001^{a}$ \\
\hline 16 & 506 & 211 & 295 & $87(17.2)$ & $20(9.5)$ & $67(22.7)$ & $<0.001^{\mathrm{a}}$ & $41(8.1)$ & $7(3.3)$ & $34(11.5)$ & $<0.001^{a}$ \\
\hline 17 & 421 & 171 & 250 & $91(21.6)$ & $19(11.1)$ & $72(28.8)$ & $<0.001^{\mathrm{a}}$ & $40(9.5)$ & $9(5.3)$ & $31(12.4)$ & $<0.001^{a}$ \\
\hline 18 & 602 & 246 & 356 & $148(24.6)$ & $36(14.6)$ & $112(31.5)$ & $<0.001^{\mathrm{a}}$ & 68 (11.3) & $15(6.1)$ & 53 (14.9) & $<0.001^{\mathrm{a}}$ \\
\hline $15-18$ & 2136 & 877 & 1259 & $438(20.5)$ & $108(12.3)$ & $330(26.2)$ & $<0.001^{\mathrm{a}}$ & $189(8.8)$ & $44(5.0)$ & 145 (11.5) & $<0.001^{\mathrm{a}}$ \\
\hline Total & 7361 & 3465 & 3896 & 917 (12.5) & $318(9.2)$ & 599 (15.4) & $<0.001^{a}$ & 668 (9.1) & $254(7.3)$ & $414(10.6)$ & $<0.001^{a}$ \\
\hline
\end{tabular}

inferred from those publications demonstrated a rate of increase similar to that which we observed, ${ }^{3,6,11,12}$ though higher rates too occurred..$^{5,7,14,15}$ When evaluated separately, boys and girls showed varyingly an increase $\mathrm{s}^{3,6,7,13,14,15}$ or no statistically significant change $\mathrm{e}^{4,6,13,14,16}$ (Table 2).

\subsection{Prevalence of migraine symptoms}

Of all the major migraine features, moderate or severe pain intensity was the most common, presenting in $99 \%$ of the migraineurs, in all age groups and both genders. Phonophobia (88\%) and photophobia (82\%) followed (Fig. 2). A high frequency of headache (OR: $1.652717,95 \%$ CI: $1.2017-2.273007$, $p=0.002$ ), a uni/bilateral location (OR: 1.460619, 95\% CI: 1.05892-2.014702, $p=0.021$ ), phonophobia (OR: 1.860171, 95\% CI: 1.313793-2.633776, $p<0.001)$ and photophobia (OR: 1.822099, 95\% CI: 1.212395-2.738417, $p=0.004$ ) were reported significantly more commonly, whereas vomiting presented much more rarely (OR: 0.6620754, 95\% CI: $0.4610252-0.9508023, p=0.026)$ in girls than in boys. In general, vomiting was the least common symptom in both genders.

\subsection{Change in migraine symptom prevalence across age groups}

The frequency and duration of headache was low in the youngest children and gradually became higher with advancing age (Fig. 3), both in boys and girls. Nausea and vomiting displayed a decreasing tendency. With increasing age, a pulsating character became more prevalent in boys, while a uni/bilateral location, photophobia and phonophobia did so only in girls. All these changes proved significant in logistic regression analysis, and the changes in frequency, uni/bilaterality, nausea (only in boys), vomiting (only in girls)

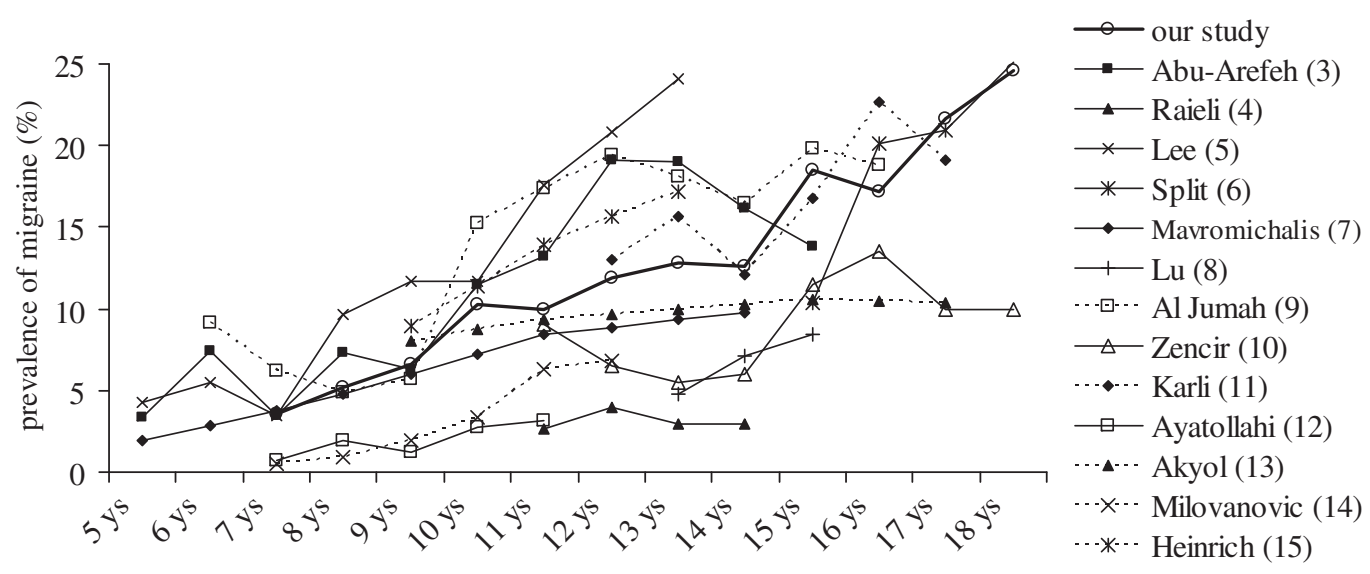

Fig. 1 - Changes in prevalence (\%) of migraine across various childhood age groups in different studies. References in parentheses. 
Table 2 - Poisson regression analysis of trends of changes in the prevalence of migraine across ages and genders.

\begin{tabular}{|c|c|c|c|c|c|}
\hline Study & Age & Gender & Change in prevalence & IRR [95\% CI] & $p$ value \\
\hline \multirow[t]{3}{*}{ Our study } & $7-18 \mathrm{yr}$ & Boys + girls & $\uparrow$ & $1.15[1.13-1.18]$ & $<0.001^{\mathrm{a}}$ \\
\hline & & Boys & $\uparrow$ & $1.07[1.04-1.11]$ & $<0.001^{\mathrm{a}}$ \\
\hline & & Girls & $\uparrow$ & $1.20[1.17-1.23]$ & $<0.001^{\mathrm{a}}$ \\
\hline \multirow[t]{3}{*}{ Abu-Arafeh ${ }^{3}$} & $5-15 \mathrm{yr}$ & Boys + girls & $\uparrow$ & $1.16[1.10-1.23]$ & $<0.001^{\mathrm{a}}$ \\
\hline & & Boys & $\uparrow$ & $1.13[1.04-1.22]$ & $0.002^{\mathrm{a}}$ \\
\hline & & Girls & $\uparrow$ & $1.20[1.11-1.29]$ & $<0.001^{\mathrm{a}}$ \\
\hline \multirow[t]{3}{*}{ Raieli $^{4}$} & $11-14 \mathrm{yr}$ & Boys + girls & NS & $1.01[0.75-1.35]$ & 0.963 \\
\hline & & Boys & NS & $0.71[0.46-1.12]$ & 0.138 \\
\hline & & Girls & NS & $1.39[0.93-2.10]$ & 0.111 \\
\hline $\operatorname{Lee}^{5}$ & $5-13 \mathrm{yr}$ & Boys + girls & $\uparrow \uparrow$ & $1.27[1.20-1.35]$ & $<0.001^{\mathrm{a}}$ \\
\hline \multirow[t]{3}{*}{ Split $^{6}$} & $15-19 \mathrm{yr}$ & Boys + girls & $\uparrow$ & $1.10[1.02-1.18]$ & $0.017^{\mathrm{a}}$ \\
\hline & & Boys & $\uparrow \uparrow$ & $1.30[1.09-1.56]$ & $0.004^{\mathrm{a}}$ \\
\hline & & Girls & NS & $1.07[0.99-1.16]$ & 0.109 \\
\hline \multirow[t]{3}{*}{ Mavromichalis $^{7}$} & $4-15 \mathrm{yr}$ & Boys + girls & $\uparrow \uparrow$ & $1.58[1.35-1.84]$ & $<0.001^{\mathrm{a}}$ \\
\hline & & Boys & $\uparrow \uparrow$ & $1.33[1.05-1.68]$ & $0.018^{a}$ \\
\hline & & Girls & $\uparrow \uparrow$ & $1.77[1.45-2.17]$ & $<0.001^{\mathrm{a}}$ \\
\hline Karli $^{11}$ & $12-17 \mathrm{yr}$ & Boys + girls & $\uparrow$ & $1.10[1.04-1.17]$ & $0.001^{\mathrm{a}}$ \\
\hline \multirow[t]{2}{*}{ Ayatollahi $^{12}$} & $6-11+y r$ & Boys + girls & $\uparrow$ & $1.44[1.14-1.81]$ & $0.002^{\mathrm{a}}$ \\
\hline & $11-17+y r$ & Girls & NS & 0.94 [0.84-1.05] & 0.267 \\
\hline \multirow[t]{3}{*}{ Akyol $^{13}$} & $9-17 \mathrm{yr}$ & Boys + girls & NS & $1.04[1.00-1.08]$ & 0.057 \\
\hline & & Boys & NS & $0.98[0.92-1.04]$ & 0.508 \\
\hline & & Girls & $\uparrow$ & 1.09 [1.03-1.15] & $0.002^{\mathrm{a}}$ \\
\hline \multirow[t]{3}{*}{ Milovanovic ${ }^{14}$} & $7-12 \mathrm{yr}$ & Boys + girls & $\uparrow \uparrow$ & $1.63[1.31-2.02]$ & $<0.001^{\mathrm{a}}$ \\
\hline & & Boys & NS & 1.38 [0.99-1.92] & 0.060 \\
\hline & & Girls & $\uparrow \uparrow$ & $1.80[1.35-2.40]$ & $<0.001^{\mathrm{a}}$ \\
\hline \multirow[t]{3}{*}{ Heinrich $^{15}$} & $9-14 \mathrm{yr}$ & Boys + girls & $\uparrow \uparrow$ & $1.38[1.24-1.54]$ & $<0.001^{\mathrm{a}}$ \\
\hline & & Boys & $\uparrow \uparrow$ & $1.37[1.17-1.59]$ & $<0.001^{\mathrm{a}}$ \\
\hline & & Girls & $\uparrow \uparrow$ & $1.40[1.20-1.62]$ & $<0.001^{\mathrm{a}}$ \\
\hline
\end{tabular}

Note: $\uparrow:$ increasing prevalence at a rate similar to ours; $\uparrow \uparrow:$ increasing prevalence at a rate higher than ours; NS: no significant change in prevalence rate; IRR: incidence rate ratio.

a Statistically significant.

and phonophobia remained significant in multiple regression analysis (Table 3).

\section{Discussion}

The present school-based questionnaire study demonstrated an overall prevalence of migraine with and without aura in the age group of $7-18$ years of $12.5 \%$, a level situated in the higher range of the results described in similar surveys. ${ }^{17,18}$ Although we found no difference in the response rate-related prevalence of migraine in the 7-14-year-old pupils, such a bias can not be excluded in the adolescents.

The steady increase in the prevalence of migraine peaking at the end of the 4 th decade of life, is well established, ${ }^{19}$ and increases from young childhood to adulthood have also been demonstrated. ${ }^{3,5-7,9-12,14,15,20,21}$ We confirmed this finding in both boys and girls. Studies involving both children and adults tend to apply an identical minimum required duration of headache for all ages: those focusing on adults commonly

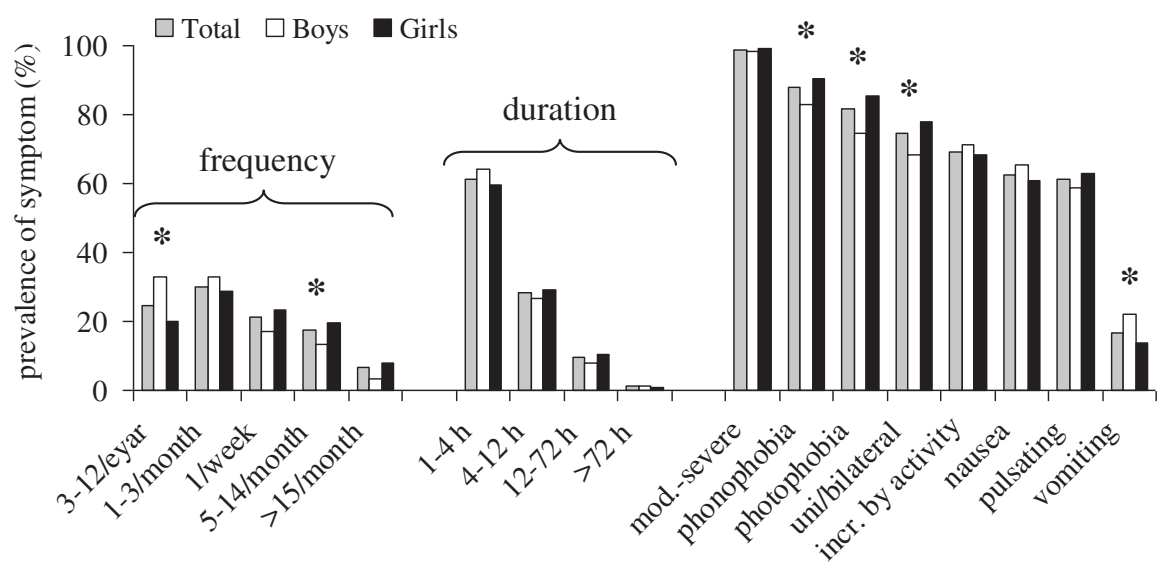

Fig. 2 - Prevalence of frequency, duration and symptoms of migraine attacks in the overall population. *: Statistically significant difference between boys and girls. 

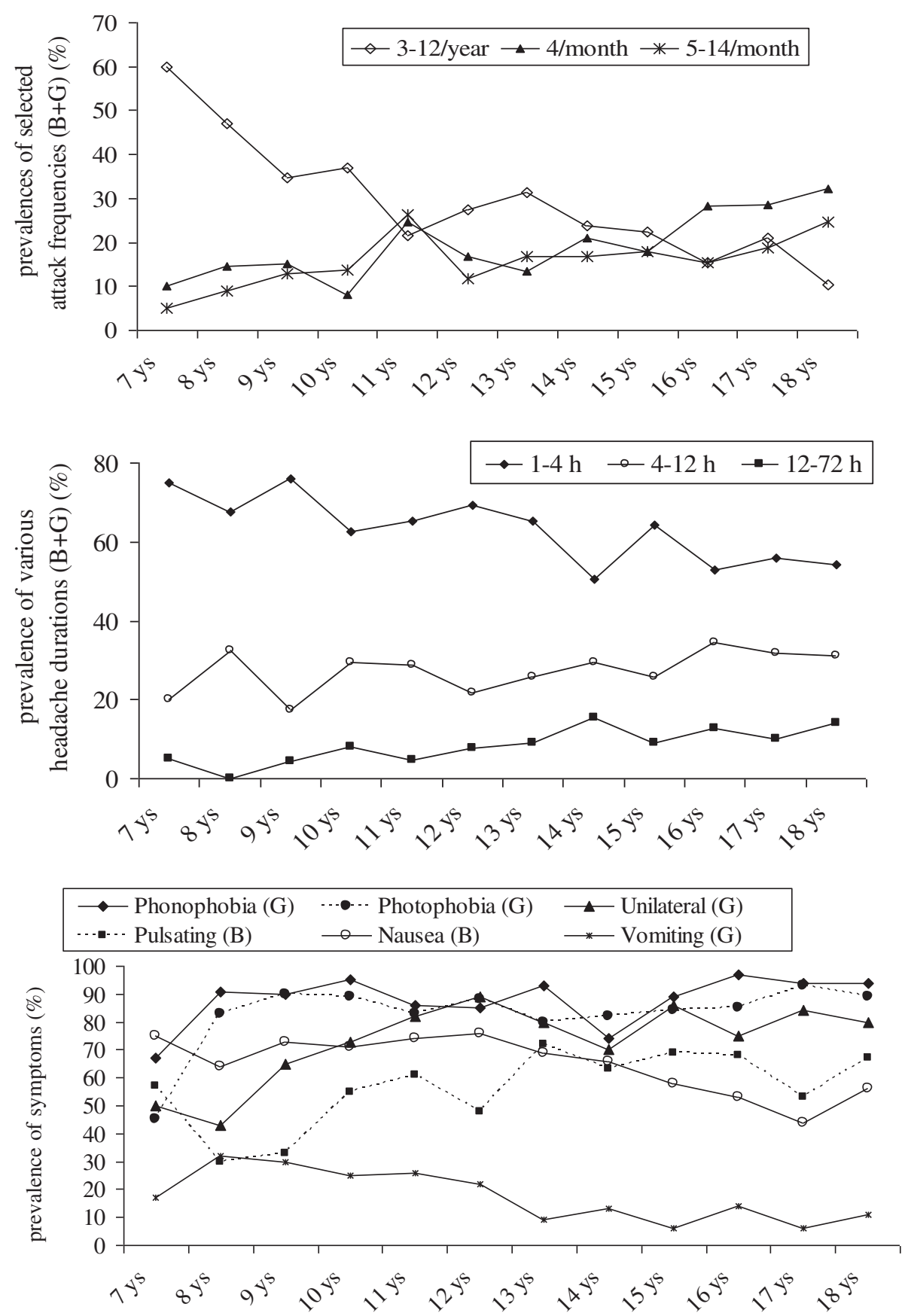

Fig. 3 - Changes in frequency, duration and some other symptoms of migraine attacks across age groups. Dashed line: significant in logistic regression analysis, continuous line: significant in both logistic and multiple regression analyses. B: boys, G: girls.

stipulate $4 \mathrm{~h},{ }^{22-25}$ whilst those few relating mostly to children and adolescents but including a proportion over the age of 18, apparently uniformly accept a 1 or 2 -h limit (for adult migraineurs too). ${ }^{6,26}$ The prevalence in childhood is underestimated by the previous approach, whilst that in adults is overestimated by the latter approach. Surveys based on the IHS-1 criteria, including children both under and over 15 years of age, commonly do not specify if they made distinction in the minimally required duration of headache. ${ }^{9,10,16,27}$ Strict adherence to this criterion as suggested by IHS-1 or ICHD-II would probably result in a drop in the age-related prevalence at the age of 15, or in adulthood, as noted in our study. Most published adult surveys indicated a 1.2-1.4-times higher prevalence of migraine when a 1-h limit or no limit was applied, compared with the prevalence based on a 4-h limit. With the requirement of a 4-h duration for adolescents, we observed the much lower prevalence of $8.8 \%$, a value in accord with the rate of $9.6 \%$ found in Hungarian adults in $2000 .^{28}$

Many authors have suggested the elimination of any time limit for the diagnosis of migraine during childhood which 
Table 3 - Logistic regression and multiple regression analyses of trends of changes in frequency of migraine features between 7 and 18 years of age.

Logistic regression analysis of trends of changes in frequency of migraine features between 7 and 18 years of age

\begin{tabular}{|c|c|c|c|c|c|c|c|c|c|}
\hline & \multicolumn{3}{|c|}{ Boys + girls } & \multicolumn{3}{|c|}{ Boys } & \multicolumn{3}{|c|}{ Girls } \\
\hline & Trend & OR $[95 \% \mathrm{CI}]$ & $p$ value & Trend & OR $[95 \% \mathrm{CI}]$ & $p$ value & Trend & OR $[95 \% \mathrm{CI}]$ & $p$ value \\
\hline Frequency & $\uparrow$ & $1.18[1.12-1.23]$ & $<0.001^{\mathrm{a}}$ & $\uparrow$ & $1.14[1.05-1.24]$ & $0.001^{\mathrm{a}}$ & $\uparrow$ & $1.17[1.10-1.25]$ & $<0.001^{\mathrm{a}}$ \\
\hline Duration & $\uparrow$ & $1.08[1.03-1.13]$ & $0.001^{\mathrm{a}}$ & $\uparrow$ & $1.08[1.01-1.17]$ & $0.037^{\mathrm{a}}$ & $\uparrow$ & $1.07[1.02-1.13]$ & $0.011^{\mathrm{a}}$ \\
\hline Uni/bilateral & $\uparrow$ & $1.09[1.04-1.15]$ & $<0.001^{\mathrm{a}}$ & & $1.04[0.96-1.12]$ & 0.359 & $\uparrow$ & $1.11[1.04-1.18]$ & $0.001^{\mathrm{a}}$ \\
\hline Non-pulsating & NS & $0.96[0.92-1.01]$ & 0.09 & $\downarrow$ & $0.91[0.84-0.98]$ & $0.012^{\mathrm{a}}$ & NS & $1.00[0.95-1.06]$ & 0.981 \\
\hline Increased by physical activity & NS & $0.98[0.93-1.03]$ & 0.40 & NS & $0.98[0.90-1.08]$ & 0.727 & NS & $0.98[0.92-1.05]$ & 0.542 \\
\hline Severe & NS & $1.02[0.85-1.23]$ & 0.84 & & $0.96[0.72-1.28]$ & 0.774 & NS & $1.04[0.81-1.34]$ & 0.737 \\
\hline Nausea & $\downarrow$ & $0.92[0.88-0.96]$ & $<0.001^{\mathrm{a}}$ & $\downarrow$ & $0.90[0.83-0.97]$ & $0.006^{\mathrm{a}}$ & $\downarrow$ & $0.94[0.89-0.99]$ & $0.018^{\mathrm{a}}$ \\
\hline Vomiting & $\downarrow$ & $0.86[0.82-0.91]$ & $<0.001^{\mathrm{a}}$ & $\downarrow$ & $0.90[0.82-0.98]$ & $0.019^{a}$ & $\downarrow$ & $0.86[0.80-0.92]$ & $<0.001^{\mathrm{a}}$ \\
\hline Photophobia & $\uparrow$ & $1.09[1.03-1.14]$ & $0.002^{\mathrm{a}}$ & NS & $1.05[0.96-1.14]$ & 0.300 & $\uparrow$ & $1.08[1.01-1.16]$ & $0.026^{a}$ \\
\hline Phonophobia & $\uparrow$ & $1.07[1.01-1.14]$ & $0.024^{\mathrm{a}}$ & NS & $1.00[0.91-1.10]$ & 0.948 & $\uparrow$ & $1.10[1.01-1.20]$ & $0.027^{a}$ \\
\hline
\end{tabular}

Multiple regression analysis of trends of changes in frequency of migraine features between 7 and 18 years of age

\begin{tabular}{|c|c|c|c|c|c|c|c|c|c|}
\hline & \multicolumn{3}{|c|}{ Boys + girls } & \multicolumn{3}{|c|}{ Boys } & \multicolumn{3}{|c|}{ Girls } \\
\hline & Trend & OR $[95 \% \mathrm{CI}]$ & $p$ value & Trend & OR $[95 \% \mathrm{CI}]$ & $p$ value & Trend & OR [95\% CI] & $p$ value \\
\hline Frequency & $\uparrow$ & $1.43[1.26-1.62]$ & $<0.001^{\mathrm{a}}$ & $\uparrow$ & $1.36[1.08-1.71]$ & $0.010^{\mathrm{a}}$ & $\uparrow$ & $1.43[1.23-1.67]$ & $<0.001^{\mathrm{a}}$ \\
\hline Duration & NS & 1.11 [0.90-1.37] & 0.32 & NS & $1.10[0.74-1.63]$ & 0.645 & NS & $1.09[0.85-1.41]$ & 0.505 \\
\hline Uni/bilateral & $\uparrow$ & $1.61[1.15-2.26]$ & $0.006^{a}$ & & NA & NA & $\uparrow$ & $1.58[1.03-2.43]$ & $0.035^{\mathrm{a}}$ \\
\hline Non-pulsating & & NA & NA & NS & $0.70[0.41-1.21]$ & 0.199 & & NA & NA \\
\hline Nausea & NS & $0.90[0.64-1.25]$ & 0.52 & $\downarrow$ & $0.47[0.26-0.083]$ & $0.010^{\mathrm{a}}$ & NS & $1.01[0.68-1.52]$ & 0.947 \\
\hline Vomiting & $\downarrow$ & $0.44[0.29-0.68]$ & $<0.001^{\mathrm{a}}$ & NS & $0.75[0.37-1.53]$ & 0.428 & $\downarrow$ & $0.41[0.23-0.71]$ & $0.002^{\mathrm{a}}$ \\
\hline Photophobia & NS & $1.23[0.79-1.90]$ & 0.36 & & NA & NA & NS & $0.93[0.52-1.67]$ & 0.814 \\
\hline Phonophobia & NS & $1.55[0.92-2.59]$ & 0.10 & & NA & NA & $\uparrow$ & $1.97[1.00-3.88]$ & $0.049^{a}$ \\
\hline
\end{tabular}

Note: $\uparrow / \downarrow$ : significantly increasing/decreasing trend of a symptom; NS: no significant change; NA: not applicable; OR: odds ratio.

a Statistically significant increase in symptom frequency through ages.

may question the need for a longer or any time limit for adults. Another option would be to apply a 2-h limit for those aged 15-18 years, while keeping a 1-h limit under the age of 15 and a 4-h limit over the age of 18 years. This approach would be in line with the experience that the duration of migraine episodes increases through childhood. However, this would make the diagnostic system somewhat more complicated.

Table 4 - Prevalence of migraine symptoms in migrainous children in different studies. \%: Percentage of migrainous children. Merged cells: one, other or both features present. (a): Calculated for migraine patients fulfilling all criteria.

\begin{tabular}{|c|c|c|c|c|c|c|c|c|c|}
\hline & $\begin{array}{l}\text { Studied } \\
\text { age group } \\
\text { (years) }\end{array}$ & $\begin{array}{c}\text { Uni/ } \\
\text { bilateral } \\
(\%)\end{array}$ & $\begin{array}{c}\text { Pulsating } \\
\text { (\%) }\end{array}$ & $\begin{array}{c}\text { Moderate or } \\
\text { Severe (\%) }\end{array}$ & $\begin{array}{l}\text { Increased } \\
\text { by phys. } \\
\text { activity (\%) }\end{array}$ & $\begin{array}{c}\text { Nausea } \\
(\%)\end{array}$ & $\begin{array}{c}\text { Vomiting } \\
(\%)\end{array}$ & $\begin{array}{c}\text { Photophobia } \\
(\%)\end{array}$ & $\begin{array}{c}\text { Phonophobia } \\
(\%)\end{array}$ \\
\hline Our study & $7-18$ & 74.6 & 61.4 & 98.8 & 69.3 & 62.3 & 16.8 & 81.8 & 87.9 \\
\hline Lee $^{5}$ & $5-13$ & 34.3 & 61.8 & 79.3 & 36 & 57.7 & 34.2 & 62.3 & 69.8 \\
\hline Mavromichalis $^{7}$ & $4-15$ & 61.2 & 63.9 & 100 & & 37.9 & 16.9 & 85.4 & \\
\hline $\mathrm{Lu}^{8}$ & $13-15$ & & & & & 70.4 & 59.1 & 63.5 & 80.9 \\
\hline Al Jumah ${ }^{9}$ & $6-18$ & 43 & 48 & & 62 & 70 & & 61 & 55 \\
\hline Zencir ${ }^{10}$ & $11-18$ & 10.9 & 49.5 & 18.4 & 92.3 & 43.2 & 13.6 & 75 & 88.6 \\
\hline Ayatollahi ${ }^{12}$ & $6-13$ & 81.5 & 89.5 & 94.8 & & 63 & 44.7 & 63.2 & 86.8 \\
\hline Akyol $^{13}$ & $9-17$ & 76.5 & 76.9 & 77.7 & 59.6 & 69.8 & & 75.8 & \\
\hline Kröner-Herwig ${ }^{20}$ & $7-14$ & 21.1 & 58.7 & 85.7 & 87.4 & 62.6 & & 78 & 81.5 \\
\hline Abu-Arafeh ${ }^{29}$ & $5-15$ & & & & & 86 & 56 & 77 & 69 \\
\hline Gherpelli $^{30}$ & $3-14$ & 55.9 & 75 & 89.1 & 73.6 & 67.3 & 54.9 & 81.3 & 83.4 \\
\hline Winner ${ }^{31}$ & $12-17$ & 58 & 74 & 91 & 88 & 53 & 5 & 80 & \\
\hline $\mathrm{Karli}^{32}$ & $12-17$ & 23.5 & 79.2 & 92.4 & & 43.1 & 12.9 & 55.4 & 62.5 \\
\hline Turkdogan $^{33}$ & $10-17$ & 86 & 66 & 94 & & 64 & 24 & 82 & 90 \\
\hline Unalp $^{34}$ & $14-18$ & 20.3 & 48.6 & 67 & 69 & 33.9 & 10.7 & 69.8 & 89.4 \\
\hline Özge $^{27}$ & $8-12$ & 32.5 & 54 & 86.6 & & 45.1 & 37.3 & 15.5 & 36.5 \\
\hline Wöber-Bingöl ${ }^{35}$ (a) & $3-19$ & 49.5 & 39.3 & 95.5 & 68.6 & 82.6 & 66.3 & 42.7 & 36.5 \\
\hline Gallai $^{36}$ & $2-18$ & 42.7 & 57.8 & 93.9 & 38.9 & 59.7 & 47.8 & 56.7 & 50.6 \\
\hline Ando $^{37}$ & $12-15$ & & & & & 90.1 & & 25.2 & 42.2 \\
\hline
\end{tabular}


Table 5 - Changes in the symptoms of migraine across ages in different studies. (G): girls only, (B): boys only.

\begin{tabular}{|c|c|c|c|c|c|c|c|c|}
\hline & $\begin{array}{l}\text { Studied age } \\
\text { group (years) }\end{array}$ & $\begin{array}{l}\text { Frequency of } \\
\text { headache }\end{array}$ & $\begin{array}{l}\text { Duration of } \\
\text { headache }\end{array}$ & Unilateral & $\begin{array}{l}\text { Pulsating } \\
\text { pain }\end{array}$ & Vomiting & Phonophobia & Photophobia \\
\hline Our study & $7-18$ & $\uparrow$ & $\uparrow$ & $\uparrow(G)$ & $\uparrow(\mathrm{B})$ & $\downarrow$ & $\uparrow(G)$ & $\uparrow(G)$ \\
\hline Gherpelli $^{30}$ & $3-14$ & & & & $\uparrow$ & & & \\
\hline Winner ${ }^{31}$ & $12-17$ & & & & & $\downarrow$ & $\uparrow$ & $\uparrow$ \\
\hline Karli $^{32}$ & $12-17$ & & & $\uparrow$ & $\uparrow$ & $\downarrow$ & $\uparrow$ & $\uparrow$ \\
\hline Wöber-Bingöl ${ }^{35}$ & $3-19$ & & & & & $\downarrow$ & $\downarrow$ & \\
\hline Hershey $^{38}$ & $3-18$ & & & & & & & \\
\hline Eidlitz-Markus $^{39}$ & $6-18$ & $\uparrow$ & $\uparrow$ & & & $\downarrow$ & & \\
\hline Özge ${ }^{40}$ & $8-12$ & & & & $\uparrow$ & & $\uparrow(G)$ & \\
\hline Wöber-Bingöl $^{42}$ & $3-69$ & & $\uparrow(G)$ & $\uparrow(G)$ & $\uparrow(G)$ & & $\uparrow(G)$ & $\uparrow(G)$ \\
\hline
\end{tabular}

The most common migraine symptom in our study population was moderate or severe pain, followed by phonophobia and photophobia. This parallels the findings of numerous authors on paediatric population of various ages $5,12,13,21,29-34$ (Table 4); only a few publications have reported appreciably different findings. ${ }^{27,35,36}$ Apart from the latter studies, nausea and especially vomiting are generally regarded as the least common symptoms. Higher rates of headache frequency, a uni/bilateral location, photophobia and photophobia were seen in girls, and of vomiting in boys. Ando et al. ${ }^{37}$ and Karli et al. ${ }^{32}$ reported similar findings, but Akyol et al. ${ }^{13}$ observed slightly higher rates of a pulsating character, photophobia and phonophobia in boys, and higher rates of nausea or vomiting in girls. Vomiting and phonophobia were more common in boys in the study by Wöber-Bingöl et al., ${ }^{35}$ while girls complained more commonly of the aggravating effect of physical activity.

Changes in the prevalence of symptoms as a function of age have been investigated by only a few authors. It was our experience that the frequency and duration of the attacks increase with advancing age, whereas vomiting and nausea become less prevalent. Uni/bilaterality, photophobia and phonophobia increased significantly in prevalence only in girls, while a pulsating character did so only in boys. Hershey et al. $^{38}$ observed virtually the same findings among 3-18-yearold migraineurs, and Eidlitz-Markus et al. ${ }^{39}$ did so as concerns the frequency, duration and vomiting in a 6-18-year-old paediatric population. Winner et al. ${ }^{31}$ and Karli et al. ${ }^{32}$ compared the trends between 12-14 and 15-17-year age groups, and reached similar conclusions to ours in respect of photophobia, phonophobia, nausea and vomiting; Karli et al. ${ }^{32}$ additionally observed an increasing trend of a pulsating character and a unilateral location. In a comparison of migraine groups aged 3-10 and 10-14 years, Gherpelli et al. ${ }^{30}$ detected a significant increase only in the pulsating character. No gender differences were investigated in these studies. In 2007, Özge et al. ${ }^{40}$ found a significant increase of a pulsating character in both boys and girls among 8-12-year-old schoolchildren, and an increasing trend of phonophobia only in girls. In contrast, Wöber-Bingöl et al. ${ }^{35,41}$ experienced a decreasing tendency of vomiting in both boys and girls among 3-19-year-old children, and a similar trend of nausea in boys and that of aggravation by physical activity, photophobia and phonophobia only in girls. The same group reported changes in symptoms nearly identical with our experiences in the much wider age range of 3-69-year-old female migraineurs. ${ }^{42}$ All these results reveal a fairly congruent tendency of the changes in the prevalence of migraine features in children (Table 5).

\section{Conclusions}

The prevalence of migraine depends on a number of inherent patient-related factors and environmental effects. However, methodological variances in epidemiological studies may cause undue differences. The increase in the duration of migraine with advancing age serves as the basis for the application of different minimum time limits for children and adults in diagnostic criteria. However, this excludes those (whose numbers probably decrease with age) who experience shorter attacks with migraine characteristics. A further problem is that increase of the limit from $1 \mathrm{~h}$ at the end of childhood to $4 \mathrm{~h}$ for adults causes an excessive drop in prevalence, and further modification of this criterion appears to be needed.

The increasing age influences not only the prevalence and the duration of migraine, but also the frequencies of other features. These changes have much less effect than the minimum required duration of headache on the estimated prevalence, as they act not as single, i.e. obligatory requirements, but are only some of other optional migraine criteria, and the diagnosis of can be established even if one or other of them is not yet present. Nevertheless, the changing features in childhood migraine must be an important consideration in studies on childhood migraine.

\section{Acknowledgement}

The authors are grateful to Professor Dr Domokos Boda for reviewing the manuscript.

\section{R E F E R E N C E S}

1. Headache Classification Committee of the International Headache Society. Classification and diagnostic criteria for headache disorders, cranial neuralgias, and facial pain. Cephalalgia 1988;88(Suppl. 7):1-96.

2. Headache Classification Subcommittee of the International Headache Society. The international classification of headache disorders, 2nd edition. Cephalalgia 2004;24(Suppl. 1):1-160. 
3. Abu-Arafeh I, Russell G. Prevalence of headache and migraine in schoolchildren. BMJ 1994;309:765-9.

4. Raieli V, Raimondo D, Cammalleri R, Camarda R. Migraine headaches in adolescents: a student population-based study in Monreale. Cephalalgia 1995;15:5-12.

5. Lee LH, Olness KN. Clinical and demographic characteristics of migraine in urban children. Headache 1997;37:269-76.

6. Split W, Neuman W. Epidemiology of migraine among students from randomly selected secondary schools in Lodz. Headache 1999;39:494-501.

7. Mavromichalis I, Anagnostopoulos D, Metaxas N, Papanastassiou E. Prevalence of migraine in schoolchildren and some clinical comparisons between migraine with and without aura. Headache 1999;39:728-36.

8. Lu S-R, Fuh J-L, Juang K-D, Wang S-J. Migraine prevalence in adolescents aged $13 \pm 15$ : a student population-based study in Taiwan. Cephalalgia 2000;20:479-85.

9. Al Jumah M, Awada A, Al Azzam S. Headache syndromes amongst schoolchildren in Riyadh, Saudi Arabia. Headache 2002;42:281-6.

10. Zencir M, Ergin H, Sahiner T, Kilic I, Alkis E, Ozdel L, et al. Epidemiology and symptomatology of migraine among school children: Denizli urban area in Turkey. Headache 2004;44:780-5.

11. Karli N, Akis N, Zarifoglu M, Akgöz S, Irgil E, Ayvacioglu U, Calisir N, Haran N, Akdogan Ö. Headache prevalence in adolescents aged 12 to 17: a student-based epidemiological study in Bursa. Headache 2006;46:649-55.

12. Ayatollahi SMT, Khosravi A. Prevalence of migraine and tensiontype headache in primary-school children in Shiraz. East Mediterr Health J 2006;12:809-17.

13. Akyol A, Kiylioglu N, Aydin I, Erturk A, Kaya E, Telli E, et al. Epidemiology and clinical characteristics of migraine among school children in the Menderes region. Cephalalgia 2007;27:781-7.

14. Milovanovic M, Jarebinski M, Martinovic Z. Prevalence of primary headaches in children from Belgrade, Serbia. Eur J Paediatr Neurol 2007;11:136-41.

15. Heinrich M, Morris L, Kröner-Herwig B. Self-report of headache in children and adolescents in Germany: possibilities and confines of questionnaire data for headache classification. Cephalalgia 2009;29:864-72.

16. Ayatollahi SMT, Moradi F, Ayatollahi SAR. Prevalences of migraine and tension-type headache in adolescent girls of Shiraz (Southern Iran). Headache 2002;42:287-90.

17. Stovner LJ, Andree C. Prevalence of headache in Europe: a review for the Eurolight project. J Headache Pain 2010;11:289-99.

18. Abu-Arafeh I, Razak S, Sivaraman B, Graham C. Prevalence of headache and migraine in children and adolescents: a systematic review of population-based studies. Dev Med Child Neurol 2010;52:1088-97.

19. Stewart WF, Lipton RB, Celentano DD, Reed ML. Prevalence of migraine headache in the United States. Relation to age, income, race, and other sociodemographic factors. J Am Med Assoc 1992;267:64-9.

20. Kröner-Herwig B, Heinrich M, Morris. Headache in German children and adolescents: a population-based epidemiological study. Cephalalgia 2007;27:519-27.

21. Laurell K, Larsson B, Eeg-Olofsson O. Prevalence of headache in Swedish schoolchildren, with a focus on tension-type headache. Cephalalgia 2004;24:380-8.

22. Köseoglu E, Naçar M, Talaslioglu A, Çetinkaya F. Epidemiological and clinical characteristics of migraine and tension type headache in 1146 females in Kayseri, Turkey. Cephalalgia 2003;23:381-8.

23. Deleu D, Khan MA, Al Shehab TAH. Prevalence and clinical characteristics of headache in a rural community in Oman. Headache 2002;42:963-73.
24. Kececi H, Dener S. Epidemiological and clinical characteristics of migraine in Sivas, Turkey. Headache 2002;42:275-80.

25. Ho K-H, Ong BK-C. A community-based study of headache diagnosis and prevalence in Singapore. Cephalalgia 2003;23:6-13.

26. Bigal ME, Lipton RB, Winner P, Reed ML, Diamond S, et al., on behalf of the AMPP Advisory Group. Migraine in adolescents. Association with socioeconomic status and family history. Neurology 2007;69:16-25.

27. Özge A, Bugdayci R, Sasmaz T, Kaleagasi H, Kurt Ö, Karakelle A, Tezcan H, Siva A. The sensitivity and specificity of the case definition criteria in diagnosis of headache: a school-based epidemiological study of 5562 children in Mersin. Cephalalgia 2002;22:791-8.

28. Bánk J, Márton S. Hungarian migraine epidemiology. Headache 2000;40:164-9.

29. Abu-Arafeh I, Russell G. Prevalence and clinical features of abdominal migraine compared with those of migraine headache. Arch Dis Child 1995 May;72(5):413-7.

30. Gherpelli JLD, Poetscher LMN, Souza AMMH, Bosse EMB, Rabello GD, Diamnet A, et al. Migraine in childhood and adolescence. A critical study of the diagnostic criteria and the influence of age on clinical findings. Cephalalgia 1998;18:333-41.

31. Winner P, Rothner AD, Putnam DG, Asgharnejad M. Demographic and migraine characteristics of adolescents with migraine: Glaxo Wellcome Clinical Trials' Database. Headache 2003;43:451-7.

32. Karli N, Akgöz S, Zarifoglu M, Akis N, Erer S. Clinical characteristics of tension-type headache and migraine in adolescents: a student-based study. Headache 2006;46:399-412.

33. Turkdogan D, Cagirici S, Soylemez D, Sur H, Bilge C, Turk U. Characteristic and overlapping features of migraine and tension-type headache. Headache 2006;46:461-8.

34. Unalp A, Dirik E, Kurul S. Prevalence and clinical findings of migraine and tension-type headache in adolescents. Pediatr Int 2007;49:943-9.

35. Wöber-Bingöl C, Wöber C, Wagner-Ennsgraber C, Zebenholzer K, Vesely C, Geldner J, Karwautz A. IHS criteria and gender: a study on migraine and tension-type headache in children and adolescents. Cephalalgia 1996;16:107-12.

36. Gallai V, Sarchielli P, Carboni F, Benedetti P, Mastropaolo C, Puca F. Applicability of the 1988 IHS criteria to headache patients under the age of 18 years attending 21 Italian headache clinics. Juvenile Headache Collaborative Study Group. Headache 1995;35:146-53.

37. Ando N, Fujimoto S, Ishikawa T, Teramoto J, Kobayashi S, Hattori A, Togari H. Prevalence and features of migraine in Japanese junior high school students aged 12-15 yr. Brain Dev 2007;29:482-5.

38. Hershey AD, Winner P, Kabbouche MA, Gladstein J, Yonker M, Lewis D, Pearlman E, Linder SL, Rothner D, Powers SW. Use of the ICHD-II criteria in the diagnosis of pediatric migraine. Headache 2005;45:1288-97.

39. Eidlitz-Markus T, Gorali O, Haimi-Cohen Y, Zeharia A. Symptoms of migraine in the paediatric population by age group. Cephalalgia 2008;28:1259-63.

40. Özge A, Bugdayci R, Sasmaz T, Kaleagasi H, Kurt Ö, Karakelle A, Siva A. The linear trend of headache prevalence and some headache features in school children. Agri 2007;19(2):20-32.

41. Wöber-Bingöl C, Wöber C, Wagner-Ennsgraber C, Karwautz A, Vesely C, Zebenhoizer K, Geldner J. IHS criteria for migraine and tension-type headache in children and adolescents. Headache 1996 Apr;36(4):231-8.

42. Wöber-Bingöl C, Wöber C, Karwautz A, Auterith A, Serim M, Zebenholzer K, Aydinkoc K, Kienbacher C, Wanner C, Wessely P. Clinical features of migraine: a cross-sectional study in patients aged three to sixty-nine. Cephalalgia 2004;24:12-7. 